\title{
Edukasi Guru SD Kaligawe Semarang sebagai Upaya Peningkatan Partisipasi Masyarakat dalam Pemeliharaan Infrastruktur Pengendali Banjir
}

\author{
Henny Pratiwi Adi*, Slamet Imam Wahyudi, Hermin Poedjiastoeti \\ Prodi Teknik Sipil, Fakultas Teknik, Universitas Islam Sultan Agung, Semarang, Indonesia \\ *Corresponding Author: \\ E-mail: henni@unissula.ac.id \\ Revised: \\ 15 April 2021 \\ Accepted: \\ 15 May 2021 \\ Published: \\ 31 May 2021
}

Received:
1 January 2021

\begin{abstract}
Abstrak
Kaligawe merupakan salah satu daerah rawan banjir di Kota Semarang. Kawasan Kaligawe termasuk dalam Sub Sistem Kali Tenggang. Penanganan terhadap banjir di Kaligawe telah dilakukan oleh pemerintah berupa normalisasi sungai dan pembangunan sistem polder sebagai bagian dari sistem drainase. Untuk menjamin keberlanjutan pengelolaan sistem drainase, diperlukan keterlibatan seluruh stakeholders, termasuk partisipasi masyarakat yang bertempat tinggal di dalamnya. Di wilayah Kaligawe, ada beberapa bangunan infrastruktur pengendali banjir seperti kolam retensi, rumah pompa, pintu gerak dan saluran drainase. Bangunan infrastruktur tersebut dapat terganggu fungsinya bila masyarakat tidak peduli, seperti membuang sampah di saluran drainase, merusak kolam retensi, mengambil/mencuri peralatan di rumah pompa dan lain sebagainya. Oleh sebab itu warga di kawasan tersebut perlu mendapatkan edukasi bagaimana hidup di lingkungan sistem polder. Sekolah Dqsar (SD) Kaligawe berada di wilayah Kaligawe, dimana para guru perlu diberikan edukasi agar dapat ikut berpartisipasi dalam pemeliharaan bangunan infrastruktur pengendali banjir. Edukasi yang akan diberikan meliputi pemahaman tentang penyebab dan dampak banjir di Semarang, penanganan banjir dan bangunan infrastruktur pengendali banjir di sekitar sekolah serta mitigasi bencana dan konsep Sekolah Siaga Bencana (SSB). Hasil pre-test terhadap guru, menunjukkan bahwa guru-guru di SD Kaligawe masih banyak yang tidak memahami bangunan pengendali banjir yang ada di sekitar lingkungan kerja mereka. Melalui edukasi yang diberikan dalam penyuluhan, guru-guru bisa memahami peran yang harus dilakukan dalam menjaga keberlangsungan bangunan pengendali banjir. Hasil post-test menunjukkan tingkat pemahaman yang meningkat pada guru-guru terhadap pengendalian banjir di wilayah Kaligawe.
\end{abstract}

Kata kunci: banjir; edukasi; infrastruktur; partisipasi

\begin{abstract}
Kaligawe is one of the flood areas in the city of Semarang. Kaligawe area is included in the Kali Tenggang Sub-System. The government has handled floods in the area in the form of river normalization and construction of a polder system as part of the drainage system. To ensure the sustainability of the drainage system management, it requires the involvement of all stakeholders, including the participation of the people who live in it. In the Kaligawe area, there are several flood control infrastructure buildings such as retention ponds, pump houses, mobile gates and drainage channels. The function of these infrastructure buildings can be disrupted if the community does not care, such as throwing garbage in the drainage channels, damaging retention ponds, taking / stealing equipment at pump houses and so on. Therefore, residents in the area need to get education on how to live in a polder system environment. SD Kaligawe is located in Kaligawe area, where teachers need education in order to participate in the maintenance of flood control infrastructure. The education that
\end{abstract}




\begin{abstract}
will be provided includes understanding the causes and impacts of floods in Semarang, flood management and building flood control infrastructure as well as disaster mitigation and the concept of Disaster Alert School (SSB). The results of the pre-test conducted in this study showed that many teachers at SD Kaligawe did not understand the flood control buildings that were around their school environment. Through the education provided in counseling, teachers can understand the role that must be played in maintaining the sustainability of flood control buildings. The results of the post test showed an increased level of teachers on understanding of flood control in the Kaligawe area.
\end{abstract}

Keywords: flood; education; infrastructure; participation

\title{
PENDAHULUAN
}

Bencana banjir selalu terjadi setiap tahun di beberapa kota besar di Indonesia, termasuk di Kota Semarang. Banjir terutama terjadi pada bagian hilir Daerah Aliran Sungai (DAS), meskipun di beberapa hulu DAS juga mengalami kondisi yang serupa. Banjir terjadi disebabkan karena beberapa hal diantaranya adalah perubahan penggunaan lahan di hulu DAS, intensitas dan curah hujan yang tinggi, adanya erosi dan sedimentasi di alur sungai, menurunnya kapasitas sungai akibat adanya pemukiman penduduk dan pembuangan sampah ke sungai, kerusakan bangunan pengendali banjir, dan perencanaan sistem drainase yang kurang tepat (Wahyudi et al., 2012).

Pemerintah Kota Semarang dan Provinsi Jawa Tengah serta dukungan dari pemerintah pusat berupaya untuk melakukan penanganan banjir dan rob di Kota Semarang. Salah satu upaya yang dilakukan adalah dengan menerapkan sistem drainase yang terintegrasi dengan baik (Wahyudi \& Adi, 2020). Sistem drainase yang telah terbangun perlu ditindaklanjuti dengan pemeliharaan dan operasional yang baik (Adi \& Wahyudi, 2015). Untuk menjamin keberlanjutan pengelolaan sistem drainase, diperlukan keterlibatan seluruh stakeholders, termasuk partisipasi masyarakat yang tinggal maupun bekerja di wilayah sistem drainase (Muttaqin, 2007).

Pengetahuan tentang bencana alam pada dasarnya merupakan pengetahuan multidisipliner, artinya melibatkan banyak studi atau kajian keilmuan. Penanganan yang paling awal dilakukan dan sangat mendasar tentu saja adalah mendidik masyarakat agar sadar terhadap bencana alam. (Adi and Wahyudi, 2020). Walaupun bukan cara satu-satunya,namun pembelajaran di sekolah dapat dinilai cukup efektif untuk membuat masyarakat sadar lebih dini. Pembelajaran di sekolah secara langsung dapat menyadarkan peserta didik akan bencana yang dapat mengancam dan upaya mitigasinya. Selanjutnya, mereka dapat menyebarluaskan pengetahuan tersebut kepada keluarga dan masyarakat luas di lingkungannya.

Sekolah Dasar (SD) Kaligawe, merupakan sekolah yang berada di kawasan Sawah Besar Kaligawe. Kawasan ini merupakan daerah rawan bencana banjir. Penanganan terhadap banjir di kawasan ini telah dilakukan oleh pemerintah pusat dan pemerintah daerah. Adapun bangunan infrastruktur sistem polder yang ada di sekitar SD Kaligawe antara lain rumah pompa, kolam retensi, pintu air dan saluran drainase. Bangunan infrastruktur tersebut dapat terganggu fungsinya bila masyarakat tidak peduli, seperti membuang sampah di saluran drainase, merusak kolam retensi, mengambil/mencuri peralatan di rumah pompa dan lain sebagainya (Adi and Wahyudi, 2019). Oleh sebab itu, masyarakat di sekitarnya harus diberikan edukasi supaya memahami arti penting bangunan infrastruktur tersebut sehingga bisa ikut berpartisipasi dalam memeliharanya. Subyek dalam kegiatan pengabdian masyarakat ini adalah guru-guru di SD Kaligawe, yang diharapkan akan mentransfer ilmu pengetahuan yang disampaikan oleh pelaksana pengabdian, kepada para siswa di SD tersebut. Harapannya dengan pemberian pengetahuan sejak dini kepada para siswa, nantinya mereka akan semakin sadar untuk menjaga lingkungan dan infrastruktur pengendali banjir yang ada di sekitar lingkungan mereka, supaya tidak lagi terjadi bencana banjir. 


\section{METODE}

Kegiatan pengabdian masyarakat dilaksanakan di wilayah kerja SD Kaligawe Kota Semarang, dengan metode pelaksanaan kegiatan sebagai berikut:

1. Memberi pre-test kepada peserta untuk melihat sejauh mana pemahaman guru-guru tentang penyebab banjir, dampak banjir dan pemeliharaan infrastruktur pengendali banjir.

2. Melaksanakan presentasi dengan materi penanganan banjir dan bangunan infrastruktur pengendali banjir yang ada di kawasan Kaligawe.

3. Melaksanakan presentasi dengan materi partisipasi masyarakat dalam pemeliharaan bangunan pengendali banjir dan sekolah siaga bencana.

4. Melaksanakan post-test untuk melihat pemahaman dan respon dari peserta terhadap materi presentasi yang telah diberikan.

Kegiatan penyuluhan tentang peran serta masyarakat dalam pemeliharaan bangunan infrastruktur pengendali banjir ini dilaksanakan pada tanggal 19 Desember 2020 di Aula SD Kaligawe Semarang. Peserta penyuluhan berjumlah 23 orang. Berikut ini adalah beberapa dokumentasi pada saat pelaksanaan kegiatan edukasi pada guru-guru SD Kaligawe.

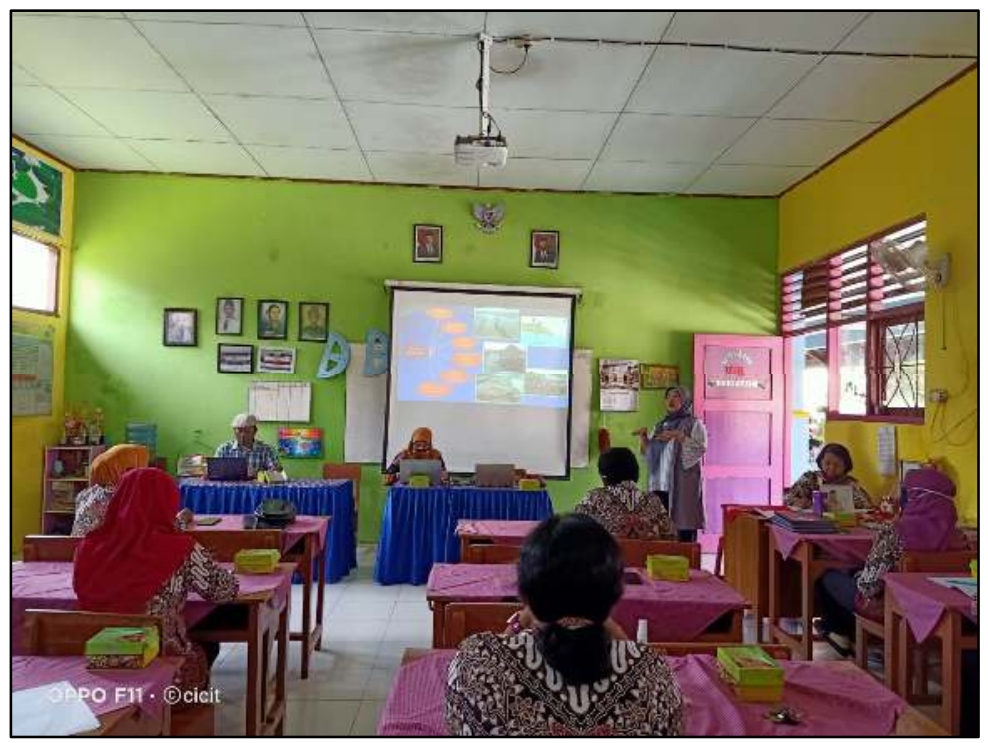

Gambar 1. Paparan dan diskusi tentang penyebab dan dampak banjir di Semarang 


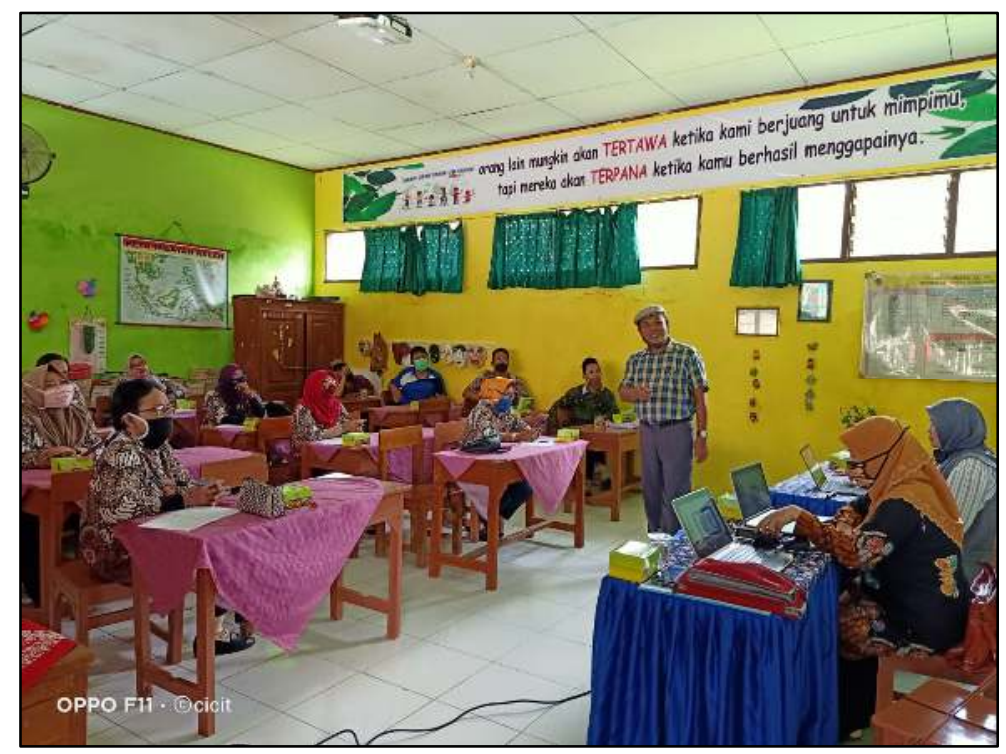

Gambar 2. Paparan dan diskusi tentang penanganan banjir dan bangunan infrastruktur pengendali banjir.

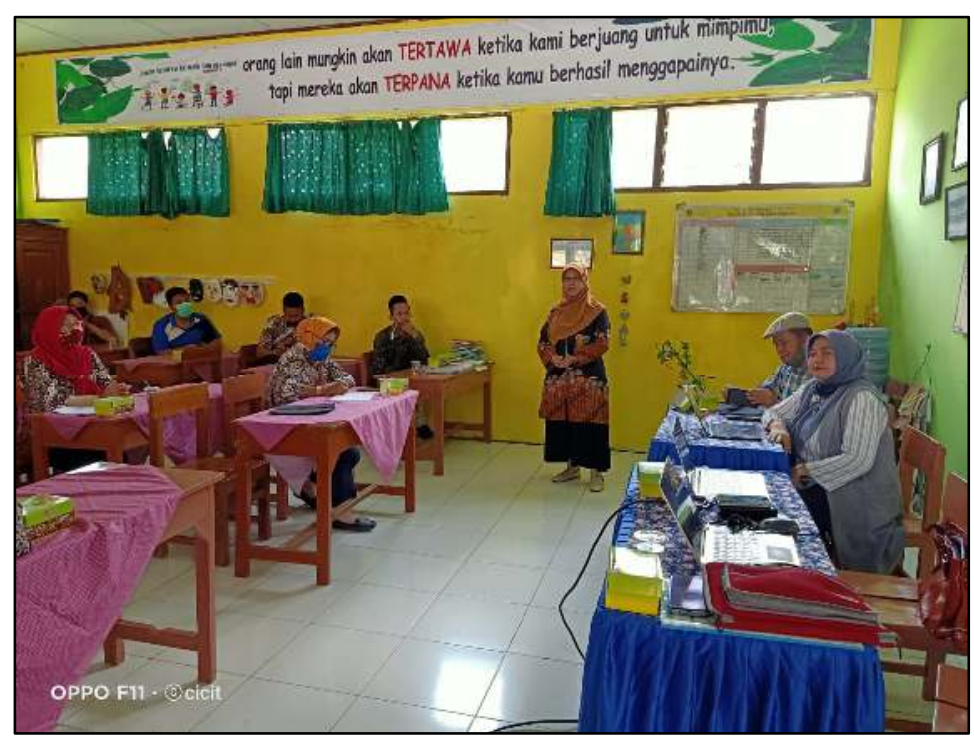

Gambar 3. Paparan dan diskusi tentang mitigasi bencana dan konsep sekolah siaga bencana.

\section{HASIL DAN PEMBAHASAN}

Terdapat tiga pokok materi yang disampaikan pada kegiatan edukasi/penyuluhan kepada para guru SD Kaligawe, yaitu tentang penyebab dan dampak banjir, penanganan banjir dan bangunan infrastruktur pendukung serta mitigasi bencana dan konsep sekolah siaga bencana.

\section{Penyebab dan Dampak Banjir}

Banjir rob menjadi bencana tiap tahun di Kota Semarang. Bahkan banjir rob tidak hanya terjadi di musim hujan. Di musim kemarau pun banjir rob masih bisa terjadi. Saat banjir rob melanda, jalan raya penuh genangan air. Transportasi tidak berjalan lancar. Peristiwa banjir rob di wilayah 
Semarang Utara disebabkan oleh beberapa faktor seperti pemanasan global, penurunan muka tanah, ketinggian gelombang laut, tingkat abrasi yang intensif, dan kerusakan drainase di wilayah Semarang Utara (Wahyudi et al., 2019).

Setidaknya 1.346 ha kawasan pesisir Kota Semarang merupakan daerah banjir rob sepanjang tahun. Areal tersebut hampir $95 \%$ merupakan kawasan permukiman padat, sehingga kerugian yang diderita warga masyarakat yang tinggal di kawasan tersebut diantaranya penyakit kulit (gatal-gatal), kehilangan 50-100 \% komponen rumah, genangan yang mempengaruhi kesehatan lingkungan serta rusaknya berbagai sarana dan prasarana. Beberapa penyebab yang secara langsung maupun tidak langsung dapat memperparah terjadinya rob antara lain : penurunan tanah akibat groundwater pumping dan beban di atas muka tanah, bertambahnya tinggi permukaan air laut, tingginya sedimentasi dan sampah, sistem drainase yang tidak tepat, curah hujan dan fenomena alam lain (Wahyudi et al., 2014).

Tabel 1. Hasil Pre dan Post Test tentang Penyebab dan Dampak Banjir

\begin{tabular}{|c|c|c|c|}
\hline \multirow{2}{*}{ No } & \multirow{2}{*}{ Pertanyaan dan Jawaban } & \multicolumn{2}{|c|}{ Prosentase Jawaban Benar } \\
\hline & & Pre-test & Post-test \\
\hline 1 & $\begin{array}{l}\text { Kota Semarang sering mengalami banjir dan rob } \\
\text { yang merupakan akibat dari: banjir, kenaikan muka } \\
\text { air laut, dan amblesan }\end{array}$ & $46,7 \%$ & $58,8 \%$ \\
\hline 2 & $\begin{array}{l}\text { Peristiwa alam berikut ini yang dapat dicegah adalah } \\
\text { : banjir }\end{array}$ & $100 \%$ & $100 \%$ \\
\hline 3 & $\begin{array}{l}\text { Berikut ini yang merupakan kegiatan manusia yang } \\
\text { dapat mengakibatkan terjadinya bencana banjir yaitu } \\
\text { : membuang sampah di sungai }\end{array}$ & $52,9 \%$ & $66,7 \%$ \\
\hline 4 & $\begin{array}{l}\text { Banjir yang terjadi di kota-kota besar pada umumnya } \\
\text { disebabkan oleh: berkurangnya daerah resapan air }\end{array}$ & $82,4 \%$ & $93,3 \%$ \\
\hline 5 & $\begin{array}{l}\text { Salah satu upaya yang dapat dilakukan untuk } \\
\text { mencegah terjadinya banjir adalah: mengadakan } \\
\text { penghijauan di lahan-lahan yang kosong }\end{array}$ & $100 \%$ & $100 \%$ \\
\hline 6 & $\begin{array}{l}\text { Pembuatan biopori dipandang dapat mengurangi } \\
\text { volume banjir, karena: laju infiltrasi meningkat }\end{array}$ & $26,7 \%$ & $29,4 \%$ \\
\hline 7 & $\begin{array}{l}\text { Intrusi air laut ke darat dapat disebabkan karena hal } \\
\text { berikut: } \\
\text { pengambilan air tanah berlebihan }\end{array}$ & $5,9 \%$ & $26,7 \%$ \\
\hline 8 & $\begin{array}{l}\text { Daerah yang setiap } 1-2 \text { tahun sekali terkena banjir } \\
\text { dengan lamanya } 1-2 \text { hari dan kedalamannya } 0,1-0,5 \\
\text { meter termasuk: daerah rawan banjir sedang }\end{array}$ & $46,7 \%$ & $58,9 \%$ \\
\hline 9 & $\begin{array}{l}\text { Jenis penyakit yang sering timbul menyusul bencana } \\
\text { banjir antara lain: ISPA, batuk, penyakit kulit }\end{array}$ & $11,8 \%$ & $66,7 \%$ \\
\hline
\end{tabular}

Berdasarkan hasil pre-test dan post-test, pemahaman peserta penyuluhan tentang penyebab dan dampak banjir di Kawasan Kaligawe mengalami peningkatan, hal ini dapat dilihat dari peningkatan prosentase jawaban benar dari peserta penyuluhan.

\section{Penanganan Banjir dan Bangunan Infrastruktur Pendukung}

Di dalam rangka mengatasi permasalahan banjir dan rob, Kota Semarang telah membagi wilayah kotanya menjadi 3 (tiga) wilayah penanganan, yaitu Wilayah Barat, Tengah dan Timur. Di Kawasan Barat, penanganan dilakukan dengan pembuatan Waduk Jatibarang, normalisasi Kanal Banjir Barat serta sistem drainase kota, yakni Kali Semarang, Kali Baru, dan Kali Asin yang merupakan satu sistem dengan kanal. Sedangkan untuk Kawasan Tengah dan Timur Semarang, penanganan banjir dan rob dilakukan dengan system polder melalui 10 kawasan polder. Sistem Polder adalah suatu cara penanganan banjir dengan bangunan fisik, yang meliputi sistem drainase, 
kolam retensi, tanggul yang mengelilingi kawasan, serta pompa dan / pintu air, sebagai satu kesatuan pengelolaan tata air tak terpisahkan. Sistem polder dipakai untuk mengeluarkan air dari dataran rendah dan juga menangkal banjir di wilayah delta dan daerah aliran sungai (Harahap, 2014).

Berikut ini adalah rekapitulasi hasil pre-test dan post-test tentang pemahaman peserta penyuluhan/edukasi terhadap penanganan banjir dan bangunan infrastruktur pengendali banjir.

Tabel 2. Hasil Pre dan Post Test tentang Penanganan Banjir

\begin{tabular}{|c|c|c|c|}
\hline \multirow{2}{*}{ No } & \multirow{2}{*}{ Pertanyaan dan Jawaban } & \multicolumn{2}{|c|}{ Prosentase Jawaban Benar } \\
\hline & & Pre-Test & Post-Test \\
\hline 1 & $\begin{array}{l}\text { Berikut masalah yang seringkali menyertai banjir, } \\
\text { kecuali: Tanah menjadi subur }\end{array}$ & $73,3 \%$ & $78,5 \%$ \\
\hline 2 & $\begin{array}{l}\text { Banjir di kawasan Kaligawe, telah ditangani } \\
\text { pemerintah dengan: sistem polder }\end{array}$ & $94,1 \%$ & $100 \%$ \\
\hline 3 & $\begin{array}{l}\text { Penerapan sistem polder merupakan salah satu cara } \\
\text { penanggulangan banjir yang terdiri dari: kolam } \\
\text { retensi, saluran drainase, pompa, tanggul }\end{array}$ & $29,4 \%$ & $53,3 \%$ \\
\hline 4 & $\begin{array}{l}\text { Drainase sebagai salah satu infrastruktur pengendali } \\
\text { banjir perlu dikelola dengan tujuan berikut, kecuali: } \\
\text { Untuk meningkatkan taraf hidup masyarakat }\end{array}$ & $42,2 \%$ & $53,3 \%$ \\
\hline 5 & $\begin{array}{l}\text { Kondisi drainase yang baik di sekolah dan } \\
\text { lingkungan sekitar adalah: saluran drainase dapat } \\
\text { menampung dan menyalurkan air limbah dan air } \\
\text { hujan: saluran drainase dapat menampung dan } \\
\text { menyalurkan air limbah dan air hujan }\end{array}$ & $70,6 \%$ & $100 \%$ \\
\hline 6 & $\begin{array}{l}\text { Meningkatkan pengetahuan masyarakat dalam } \\
\text { menghadapi serta mengurangi dampak/resiko } \\
\text { bencana, sehingga masyarakat dapat hidup dan } \\
\text { bekerja dengan aman merupakan: Tujuan mitigasi }\end{array}$ & $47,1 \%$ & $66,7 \%$ \\
\hline 7 & $\begin{array}{l}\text { Suatu fenomena alam tergolong sebagai bencana jika } \\
\text { mengakibatkan: Korban jiwa dan kerusakan } \\
\text { lingkungan }\end{array}$ & $46,7 \%$ & $70,6 \%$ \\
\hline 8 & $\begin{array}{l}\text { Tindakan mitigasi bencana alam dilakukan: sebelum } \\
\text { terjadi bencana }\end{array}$ & $23,5 \%$ & $33,3 \%$ \\
\hline
\end{tabular}

Berdasarkan hasil pre-test dan post-test, pemahaman peserta penyuluhan tentang penanganan banjir yang telah dilakukan oleh pemerintah di Kawasan Kaligawe mengalami peningkatan, hal ini dapat dilihat dari peningkatan prosentase jawaban benar dari peserta penyuluhan. Setelah mengikuti penyuluhan ini, para guru diharapkan mampu memberikan penjelasan kepada para siswa tentang memahami jenis dan operasional bangunan infrastruktur pengendali banjir. Harapan ke depan, guru dan siswa dapat ikut serta dalam menjaga dan memelihara bangunan tersebut agar terus dapat berfungsi secara maksimal.

\section{Mitigasi Bencana dan Konsep Sekolah Siaga Bencana}

Mitigasi bencana adalah serangkaian upaya untuk mengurangi risiko bencana, baik melalui pembangunan fisik maupun penyadaran dan peningkatan kemampuan menghadapi ancaman bencana (Pasal 1 ayat 6 PP No 21 Tahun 2008 Tentang Penyelenggaraan Penanggulangan Bencana). Tujuan mitigasi bencana adalah :

- Mengurangi dampak yang ditimbulkan, khususnya bagi penduduk

- Sebagai landasan (pedoman) untuk perencanaan pembangunan

- Meningkatkan pengetahuan masyarakat dalam menghadapi serta mengurangi dampak/resiko bencana, sehingga masyarakat dapat hidup dan bekerja dengan aman 
Beberapa kegiatan mitigasi bencana di antaranya:

- pengenalan dan pemantauan risiko bencana;

- perencanaan partisipatif penanggulangan bencana;

- pengembangan budaya sadar bencana;

- penerapan upaya fisik, nonfisik, dan pengaturan penanggulangan bencana;

- identifikasi dan pengenalan terhadap sumber bahaya atau ancaman bencana;

- pemantauan terhadap pengelolaan sumber daya alam;

- pemantauan terhadap penggunaan teknologi tinggi;

- pengawasan terhadap pelaksanaan tata ruang dan pengelolaan lingkungan hidup

Sekolah Siaga Bencana (SSB) merupakan upaya membangun kesiapsiagaan sekolah terhadap bencana dalam rangka menggugah kesadaran seluruh unsur-unsur dalam bidang pendidikan baik individu maupun kolektif di sekolah dan lingkungan sekolah baik itu sebelum, saat maupun setelah bencana terjadi.

Untuk mendukung hal tersebut, pemerintah mencanangkan program Sekolah Siaga Bencana (SSB) yang bertujuan membangun budaya siap siaga bencana serta membangun ketahanan dalam menghadapi bencana. Konsep SSB tidak hanya terpaku pada unsur kesiapsiagaan, melainkan upaya pengembangan pola pikir dan pengetahuan dalam rangka mewujudkan budaya keselamatan, keamanan, dan ketahanan bagi seluruh warga sekolah. Konsep SSB memiliki dua unsur utama, yakni lingkungan belajar yang aman, serta kesiapsiagaan warga sekolah. SSB diharapkan mampu menjadi sarana optimalisasi penyampaian informasi kebencanaan di tingkat sekolah. Pencanangan program SSB diharapkan menjadi salah satu wujud penanggulangan bencana yang terpadu, terkoordinasi, dan menyeluruh sebagai upaya perlindungan kepada masyarakat akan risiko dan dampak bencana mengingat pengurangan risiko bencana bukan saja menjadi tanggung jawab pemerintah, tetapi tentunya membutuhkan sinergi dari berbagai pihak terutama warga sekolah yang diharapkan mampu mencetak bibit-bibit penerus generasi bangsa dengan kesadaran dan ketangguhan menghadapi bencana (Ginting, 2015).

Berikut ini adalah rekapitulasi hasil pre-test dan post-test tentang pemahaman peserta penyuluhan/edukasi terhadap mitigasi bencana dan sekolah siaga bencana.

Tabel 3. Hasil Pre dan Post-test Mitigasi Bencana

\begin{tabular}{|c|c|c|c|}
\hline \multirow{2}{*}{ No } & \multirow{2}{*}{ Pertanyaan dan Jawaban } & \multicolumn{2}{|c|}{ Prosentase Jawaban Benar } \\
\hline & & Pre-test & Post-test \\
\hline 1 & $\begin{array}{l}\text { Upaya sekolah dalam mendukung PRB (Penanganan } \\
\text { Risiko Bencana), antara lain: Membuat kebijakan } \\
\text { terkait PRB, Akses informasi mengenai PRB, } \\
\text { Rencana alternatif Pendidikan selama bencana }\end{array}$ & $86,7 \%$ & $94,1 \%$ \\
\hline 2 & $\begin{array}{l}\text { Peningkatan kemampuan individu atau kelompok } \\
\text { dalam melakukan kesiapsiagaan di Sekolah: P3K } \\
\text { termasuk dokter kecil, Kepramukaan, Latihan dan } \\
\text { simulasi, Ceramah tentang bencana }\end{array}$ & $40 \%$ & $52,9 \%$ \\
\hline 3 & $\begin{array}{l}\text { Tujuan Sekolah Siaga Bencana, adalah: } \\
\text { Membangun budaya siaga dan budaya aman di } \\
\text { sekolah, Menyebarluaskan dan mengembangkan } \\
\text { pengetahuan kebencanaan ke masyarakat melalui } \\
\text { jalur Pendidikan sekolah, Membangun ketahanan } \\
\text { dalam menghadapi bencana oleh warga sekolah }\end{array}$ & $52,9 \%$ & $60 \%$ \\
\hline 4 & $\begin{array}{l}\text { Parameter Sekolah Siaga Bencana adalah: } \\
\text { a. Pengetahuan, keterampilan, sikap } \\
\text { b. Sistem peringatan dini } \\
\text { c. Rencana tanggap darurat }\end{array}$ & $29,4 \%$ & $53,3 \%$ \\
\hline
\end{tabular}




\begin{tabular}{clcc}
\hline 5 & $\begin{array}{l}\text { Sistem peringatan dini yang dapat diterapkan di } \\
\text { lingkungan sekolah, adalah: } \\
\text { Sound system, Bel sekolah, Alarm }\end{array}$ & $23,5 \%$ & $26,7 \%$ \\
\hline 6 & $\begin{array}{l}\text { Upaya yang dilakukan oleh pemerintah, kelompok } \\
\text { masyarakat, keluarga dan pribadi untuk menghadapi } \\
\text { terjadinya bencana adalah: kesiapsiagaan bencana }\end{array}$ & $47,1 \%$ & $80 \%$ \\
\hline
\end{tabular}

Berdasarkan hasil kuesioner pre-test dan post-test, pemahaman peserta penyuluhan tentang mitigasi bencana dan konsep Sekolah Siaga Bencana (SSB) mengalami peningkatan, hal ini dapat dilihat dari peningkatan prosentase jawaban benar dari peserta penyuluhan. Diharapkan setelah mengikuti penyuluhan ini, guru-guru SD Kaligawe dapat memberikan pemahaman tentang bagaimana hidup di lingkungan yang rawan bencana banjir kepada siswanya

\section{KESIMPULAN}

Berdasarkan kegiatan pengabdian masyarakat yang telah dilaksanakan, maka ada beberapa hal yang dapat disimpulkan bahwa pengetahuan dan pemahaman guru-guru SD Kaligawe tentang penyebab banjir, penanganan banjir, bangunan infrastruktur pengendali banjir serta cara pemeliharaannya masih rendah. Selain itu, berdasar pada hasil post-test, terjadi peningkatan pengetahuan dan pemahaman yang cukup signifikan pada guru-guru SD Kaligawe, setelah dilakukan penyuluhan / edukasi dari tim pengabdian masyarakat.

\section{UCAPAN TERIMA KASIH}

Ucapan terima kasih disampaikan kepada Lembaga Penelitian dan Pengabdian Masyarakat (LPPM) UNISSULA yang telah mendanai kegiatan pengabdian masyarakat ini, serta Kepala Sekolah dan guru SD Kaligawe Semarang yang telah bersedia bekerja sama untuk terlaksananya kegiatan ini.

\section{DAFTAR PUSTAKA}

Adi, H. P., \& Wahyudi, S. I. (2019). Institutional Model in Management of Drainage System. International Journal of Innovative Technology and Exploring Engineering, 9(2), 10991103. https://doi.org/10.35940/ijitee.L3449.129219

Adi, H. P., \& Wahyudi, S. I. (2020). The Comparison of Institutional Model in Water Management Board - A Case Study of Management on Polder Drainage System in Semarang, Indonesia. International Journal of Sustainable Construction Engineering and Technology, 11(1), 312-322.

Adi, H. P., \& Wahyudi, S. I. (2015). Analysis of Drainage System Management in The Netherlands , France and Indonesia. Proceedings of International Conference "Integrated Solutions to Overcome The Climate Change Impact on Coastal Areas, ” 1-8.

Ginting, R. A. (2015). Studi Perencanaan Penanggulangan Banjir Kota Kuala Tungkal Kab. Tanjung Jabung Barat Propinsi Jambi. Jurnal Ilmiah Universitas Batanghari Jambi, 15(1), 45-49.

Harahap, M. A. K. (2014). Konsep Pengelolaan Drainase Sebagai Sarana dan Prasarana Perkotaan Secara Terpadu, Jurnal Pembangunan Perkotaan, Vol. 2 No.1, 9-14.

Muttaqin, A. Y. (2007). Kinerja Sistem Drainase yang Berkelanjutan Berbasis Partisipasi Masyarakat ( Studi Kasus di Perumahan Josroyo Indah Jaten Kabupaten Karanganyar). Media Teknik Sipil UNS, 2(36), 115-124. 
Wahyudi, S. I., Adi, H. P., \& Husni, F. (2020, September). Polder System to Handle Tidal Flood in Harbour Area (A Case Study in Tanjung Emas Harbour, Semarang, Indonesia). In Journal of Physics: Conference Series (Vol. 1625, No. 1, p. 012051). IOP Publishing.. https://doi.org/10.1088/1742-6596/1625/1/012051

Wahyudi, S. I., Adi, H. P., Rochim, A., \& Marot, D. (2014). Aspects of Hydrology, Tidal and Water Storage Capacity For Simulating Dike Model of Channel and Retention Basin. International Journal of Civil and Environmental Engineering IJCEE/IJENS, October.

Wahyudi, S. I., Adi, H. P., \& Bras, G. Le. (2012). The Evaluation of Land and sea level in attempts to control drainage system of tidal flood area in Semarang, Indonesia. International Commision Irrigation and Drainage (ICID) 63rd International EC Meeting \& 7th Asian Regional Conference, Adelaide, Australia.

Wahyudi, S. I., Adi, H. P., \& Lekkerkerk, J. (2019). Handling Solution Tidal Flood in Kaligawe Area by Polder System Drainage. International Journal of Innovative Technology and Exploring Engineering, 9(2), 1104-1109. https://doi.org/10.35940/ijitee.L3450.129219 